\title{
Analysis of the Current and Potential Future Climate Hazards and their Impacts on Livelihoods and Adaptation Strategies in Arid and Semiarid Lands
}

\author{
Boniface Nzuve Wambua \\ Department of Geography \& Environmental Studies, University of Nairobi, \\ P.O. Box 30197-00100 GPO, Nairobi, Kenya. \\ Email: wambua_boniface [AT] uonbi.ac.ke
}

\begin{abstract}
The study was carried out in four selected counties within the Arid and Semi-Arid Lands (ASALS) of Kenya namely Garrisa, West Pokot, Kilifi and Tana River which were under Kenya-Adaptation to Climate Change in Arid Lands (KACCAL) program. The study focun mm sed on the current and potential future climate hazards and their impacts on livelihoods and adaptation strategies within the framework of Kenya-adaptation to climate change in arid lands. The ASALS covers $80 \%$ of Kenya's land mass and support about 70 percent of the national livestock population and $90 \%$ of wildlife resources. Despite the great potential for development in the ASALS, the areas have continued experiencing great climate hazards leading to severe impacts on household livelihoods. The study methodology involved identification and assessing the major climatic hazards experienced for many years and implementation of adaptation strategies by the local communities. This involved a review of operating/ existing assessment of Climate Risks in Agriculture and Rural Development, Field visits, data collection and stakeholder consultation through a series of intensive questionnaire interviews with farmers, project Planners and managers and county officials in the four counties.
\end{abstract}

The results showed that the four counties under study have been affected by droughts, floods, gusty winds and landslides hazards associated with climate change which have affected the livelihoods of the communities living in the ASALS. The impacts have been felt in food insecurity, scarcity of water resources, loss of livestock resources, persisted crop failure, increased malnutrition cases leading to infant morbidity and mortality among others. The intervention strategies to manage the climate change impacts applied by stakeholders among other well-wishers are; distribution of food relief, provision of shelter, provision of tents, building gabions, moving families at high risk to saver grounds, construction of water dams and pans. At household level, intervention strategies used are diversification of livelihoods, growing of fodder crops to supplement the natural pasture, charcoal burning, growing of drought resistant crops among others. Subsequently, the study recommends that more awareness should be created among local communities so that they diversify their livelihoods to cope with changing climate. The stakeholder working in ASALs, County governments and National government should invest more on intervention strategies to management climate change impacts

Communities living in ASALs and other stakeholders should be trained on how to use tools and methodologies developed in order to monitor impacts of climate change in their respective counties and implement the appropriate intervention strategies to ensure households recover from impacts associated to of climate change. In other words, capacity building at community, county and national government should be a top priority.

Keywords--- Climate Change, Climate Hazards, Adaptation Strategies

\subsection{Background information}

\section{INTRODUCTION}

Climate-related hazards are a serious threat to Kenya's development especially as they affect key economic sectors such as agriculture which is the mainstay of the Kenyan economy and currently highly vulnerable to climate change. Kenya's Arid and Semi-Arid Lands (or ASALs) are home to approximately 4 million pastoralists who constitute more than $10 \%$ of Kenya's population plus other rangeland users. Extreme climatic events have long posed a significant risk to regions in Kenya, and they have contributed to making it one of the most disaster-prone countries in the world. Estimates show that Kenya experiences floods that cost about 5.5\% of GDP every seven years and drought that costs about $8 \%$ of GDP every five years. This translates to long-term fiscal liability of about $2.4 \%$ of GDP per annum. The most vulnerable areas are the Arid and Semi-Arid Lands (ASALs), which now experience droughts almost annually. This is of great concern as ASALs cover $80 \%$ of the country and accommodate approximately $30 \%$ of Kenya's population and $50 \%$ of its livestock (AEA Group, 2008).

In the light of the above situations, it is most appropriate that this study was undertaken aimed at addressing the current and potential future climate hazards and their impacts on livelihoods and adaptation strategies within the Kenya-Adaptation to Climate Change in 
Arid Lands (KACCAL) framework. The country often has food deficits as a result of periodic droughts and low access to production resources. In the ASALs, about 2 million people are permanently on famine relief, with the number rising up to 5 million during severe droughts (GoK 2015, Kirbride and Grahn, 2008).

Kenya was among the first countries in Africa to develop government plans for responses to climate change across key economic sectors. Kenya's recent National Climate Change Response Strategy (NCCRS, GoK 2010) and the National Climate Change Implementation Framework (2012) illustrate that climate change has acquired the status of a key national policy challenge. The National Climate Change Action Plan (GoK, 2013) was launched in March, 2013. This was developed through a consultative process that engaged actors across government, development partners and the private sector and civil society. In the support of climate change adaptation planning at community level, climate hazards have to be documented because they have potential to affect climate change projects areas and livelihoods.

\subsection{Justification of the study}

The ASALs which covers $80 \%$ of Kenya's land mass support about 70 percent of the national livestock population, valued at an estimated kShs.70 billion(690,000,000\$dollars). These areas also support more than 90 percent of the nation's wild game species, which are the central attraction of a tourist industry that earns in excess of Kshs 50 billion (500 million\$dollars) annually. Despite their great potential for development, the ASALs which have experienced great climate hazards leading to severe impacts on livelihoods have not been fully integrated into the national economy through adaptation strategies

\subsection{Scope and limitations}

This study was conducted in the four Kenya Adaptation to Climate Change in Arid and Semi-Arid Lands Project (KACCAL) Counties of Garissa, West Pokot, Kilifi and Tana - River.

\subsection{Methods of data collection}

\section{METHODOLOGY OF STUDY}

The study involved identification, assessing and implementing of adaptation strategies. The study is an outcome of a review of operating/ existing assessment of Climate Risks in Agriculture and Rural Development, Field visits, data collection and stakeholder consultation through a series of intensive questionnaire interviews with farmers, project Planners and managers and county officials in the four counties. Focused group discussions composed of farmers from different value chains, service providers and farmer leaders and available opinion leaders in every sub-country in the four selected counties. Scientific observations of climate hazards, together with analysis of the observed and projected climate change in the focus communities in the four counties; namely Garissa, Kilifi, Tana River, and West Pokot was used. The analysis focuses on four climatic hazards namely; Floods, drought, lightening, landslides and gusty winds.

\subsection{Identifying Adaptation Strategies}

After identifying the risks that need treatment, possibilities for reducing threats and seizing any opportunities that climate change may present thus involved identification of feasible adaptation strategies. The identification of possible strategies or actions, therefore, proceed according to possible suitable options, and were found relatively easily in various sources. However, a lot of the identified adaptation strategies may be simply possibilities, the question of how realistic, effective or desirable they will be calls for investigation within the specific context. Adaptation strategies for treatment of risks were classified according to their mode of operation as follows: avoiding the risk entirely by ceasing certain operations; taking or increasing the risk to pursue an opportunity; removing the risk source; reducing the likelihood and/or consequences e.g. building more water storage capacity, or public awareness campaigns to use water more prudently;

\subsection{Assessing Adaptation Strategies}

Having identified a list of feasible adaptation strategies, the task then was to have some kind of rational basis for choosing between the different options. There are various methods which were used to do this, depending on the kind of adaptation strategy that is sought, and possibly constraining factors such as existing methods and practices. Choosing between different adaptation strategies was determined according to their relative performance against various criteria e.g. cost, efficacy, equity, stakeholder acceptance. Regardless of the method used to ultimately choose between adaptation strategies, it was very important that the various options be assessed over as wide a range of possible futures as possible (determined by climate and non-climate factors).

\subsection{Implementing Adaptation Options}

After determining the strategy or strategies deemed to be most or more desirable, these options will then be implemented. A range of different actions may be considered and implemented, and this will generally be good practice. 


\section{RESULTS AND DISCUSSION}

\subsection{An Overview of Major Climatic Hazards in KACCAL Zones in Kenya over the Past 40 years}

Scientific observations of climate hazards, together with analysis of the observed and projected climate change in the focus communities in the four counties; namely Garissa, Kilifi, Tana River, and West Pokot is presented in the following subsections. The analysis focuses on four climatic hazards namely; Floods, drought, lightening, landslides and gusty winds.

\subsubsection{Floods}

Study review revealed floods as one of the major climatic hazard in the four counties. Garissa County has experienced floods in the following years; 1997, 1998, 2006, 2011, 2013, 2014, 2015 and 2016. In 2008, floods in Garissa triggered landslides hampering access to affected areas and displacing entire communities. In 2002 and 2012 floods were experienced in Garissa and Ijara regions due to the overflow of River Tana (ICRC 2012 and DMCN 2002). Figure 3.1 indicates some intervention measures undertaken by key stakeholders in the county. The main intervention strategy being provision of relief food by both the National and County Governments.

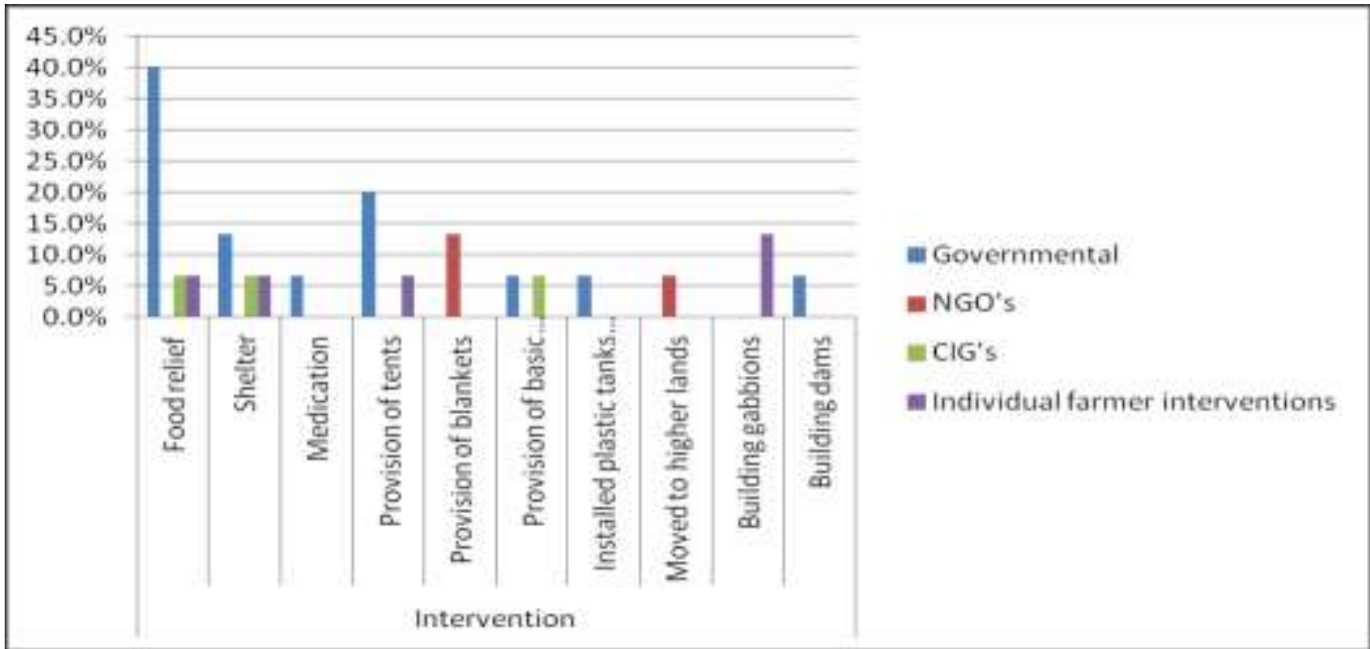

Figure 3.1: Stakeholder Interventions in mitigating floods in Garissa County

Tana River County which is is classified as a high hazard probability (HHP) of Floods also experiences Conflict and drought episodes as witnessed in the following years of floods: 1997/1998, 2002, 2012, 2013, 2014, 2015 and 2016. The effects of the rains from December 2015 resulted in floods caused by rivers bursting their banks in Tana River and other counties which led to the establishment of a total of 67 IDP camps in the county and hosting of 7788 HHs (IFRC 2016). The flat terrain and the River Tana are rich recipes for flooding during the erratic rains received in the County and as a result of heavy rains upstream of river Tana i.e. Aberdare Ranges, Mount Kenya and Nyambene Hills resulting into occasional floods. Figure 3.2 indicates some intervention measures undertaken by key stakeholders to mitigate against floods in the county.

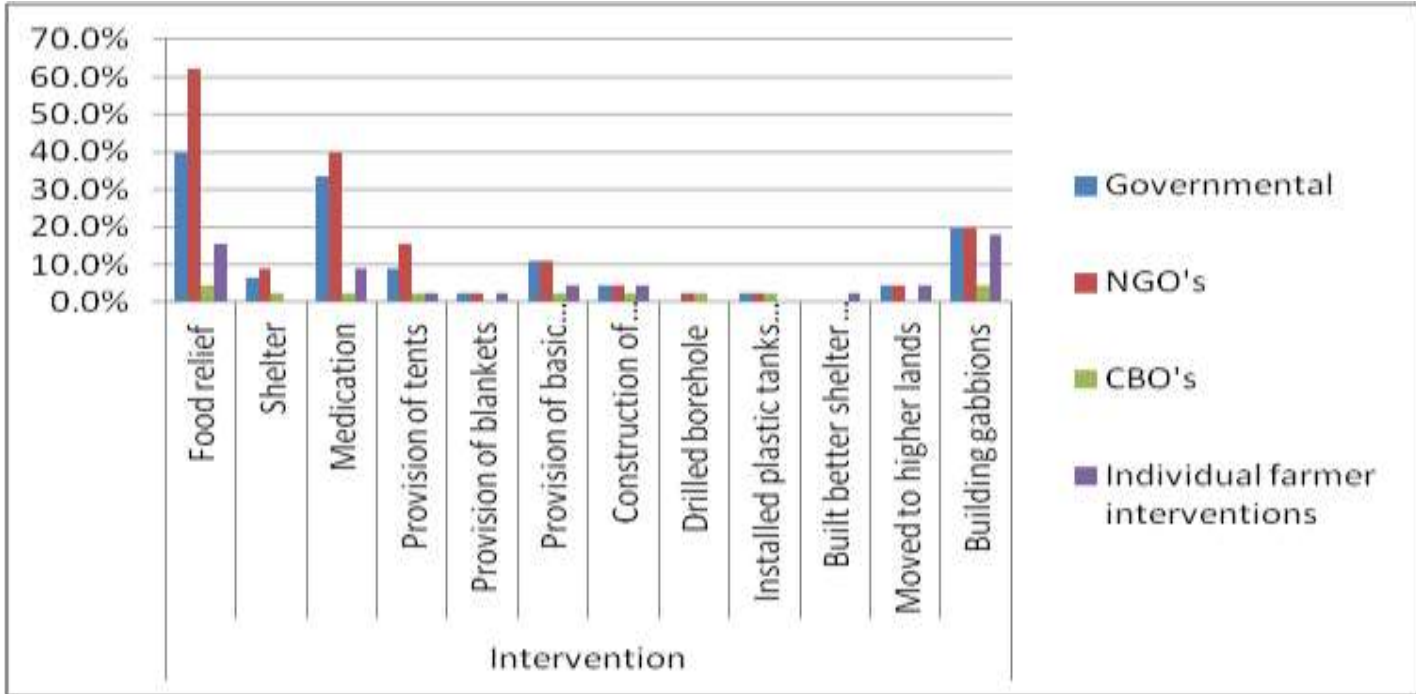

Figure 3.2: Stakeholder Interventions in mitigating floods in Tana River County 
In Kilifi County, Floods was identified as one of the main extreme weather events in the last ten years which have affected staple food crop quality and yields. In October 2015, homesteads were flooded in Ngomeni area as a result of heavy tidal waves in the Indian Ocean. The county records increased intensity and frequency in occurrence of floods in Ganze, Kaloleni and Magarini constituencies. These extreme events have had negative socio-economic impacts on almost all sectors such as health, agriculture, environment and tourism (Kilifi County IDP, 2013-2017).

Rainfall patterns in West Pokot County illustrate unpredictable cycle as heavy rains are always followed by scarce rains. Evidence of climate variability has become more pronounced through the alternating cycles of droughts and floods (Huho and Kosonei, 2014). Examples mentioned by Kenya Red Cross Society (2012), are the unpredictable cycles especially in 2004 and 2009 where droughts were interposed with floods and caused devastating impacts on crop yields (Musingi, 2013). Figure 3.3 indicates some flood intervention measures undertaken by key stakeholders in Kilifi County.

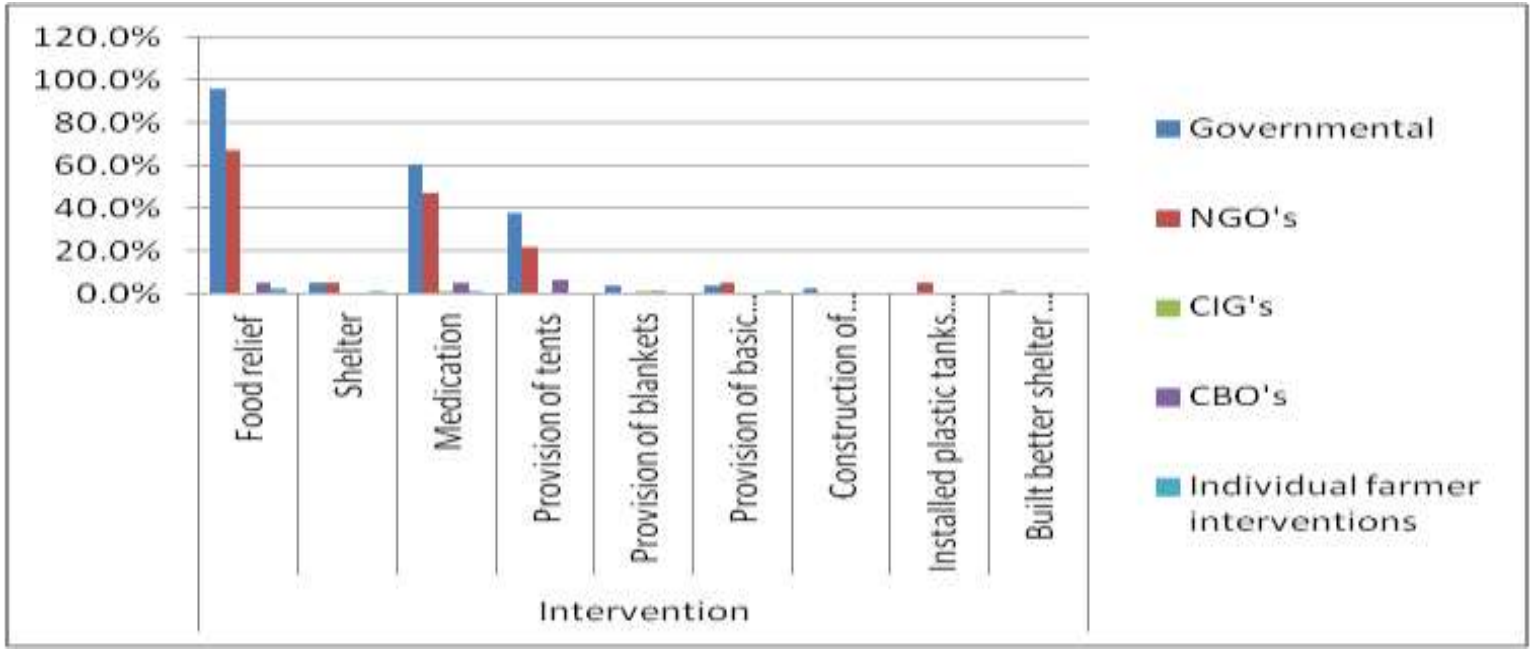

Figure 3.3: Stakeholder Interventions in mitigating floods in Kilifi County

\subsubsection{Droughts}

Garissa County is among the areas mostly affected by drought in Kenya causing pressure on the limited pastures and water resources relied on by the communities which sometimes lead to ethnic conflicts in the scramble for grazing or watering points particularly among the pastoralist communities (Nabutola, 2012). The negative influence of drought on agropastoralists includes; Death and general weakness of livestock due to lack of pasture and water; Reduced sources of income for the community and change of river course during drought hence farmers cannot irrigate during dry spells. Findings from the Global Water Initiative project selected for testing an Integrated Climate Change Adaptation Toolkit in Garissa identified the prolonged and severe drought in 2009 as a key challenge, since it negatively affected the promotion of pointof-use water treatment, and exacerbated poverty among the pastoralists who rely on their livestock as their economic mainstay. Figure 3.4 indicates drought adaptation mechanism undertaken by community members in the four KACCAL Counties. 


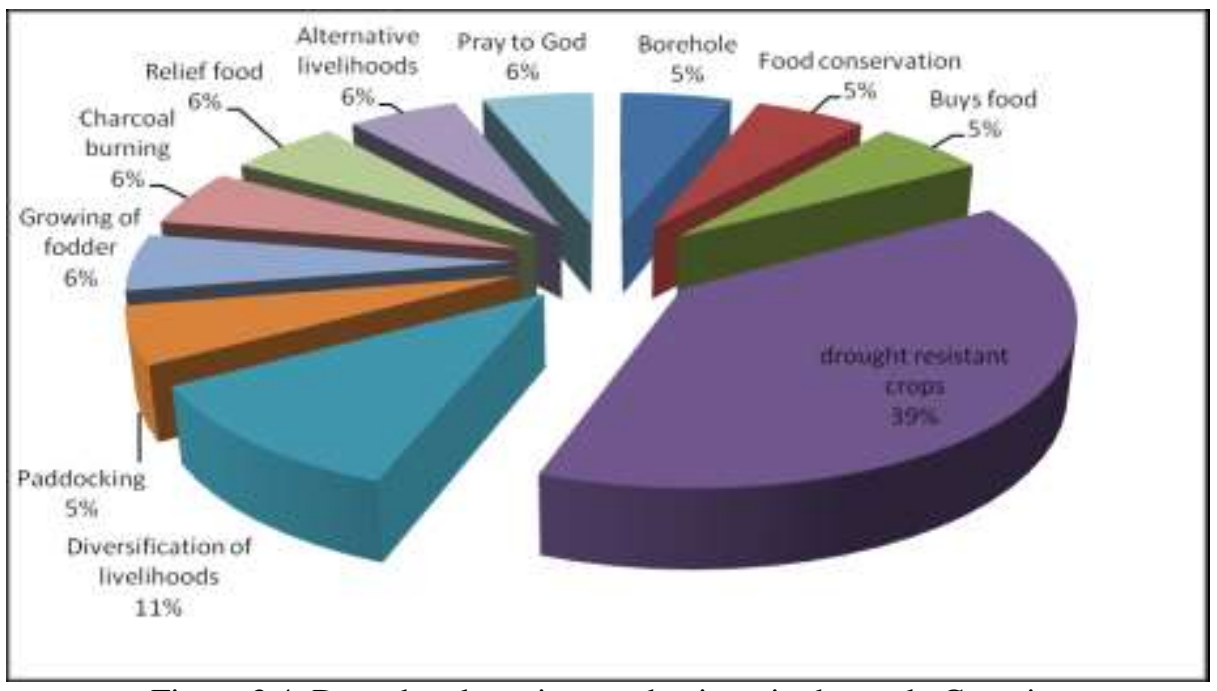

Figure.3.4: Drought adaptation mechanisms in the study Counties

Kilifi County is one of the semi-arid counties of Kenya, which houses Ganze Sub County, one of the poorest sub counties in Kenya (Kenya, 2004). Ganze is the most ASAL Sub-county of Kilifi County that has suffered from recurrent droughts for the last two decades, which has posed adverse effects on livelihoods (KFSSG, 2012). In several areas of Kilifi County, land use conflicts between wildlife and livestock or farming have reached significant levels. During the peak period of drought, many elephants move from the drought stricken Galana and Kulalu ranching areas and from as far as Tsavo East National Park to the Jilore and Soke forests. These movements, either in search of food, water, breeding grounds or in response to seasonal cycles, cause damage to crops in adjacent farms, concentrations of wildlife herds beyond the area's capacity, killing of some livestock, infestations of diseases, and loss of human life (TARDA, 2012).

The upper Tana River basin has been negatively affected by notable droughts such as the La Niña of 1999 to 2000 , and 2008 to 2009 (Oludhe 2012). These led to severe water scarcity hence increased concentrations of sediment and chemicals. Declined agricultural production and forest resources have also been witnessed since most farming is rain-fed (Jacobs,et al., 2000). Mackenzie, et al.,(2013) found that the return periods for extreme climatic events such as drought has shortened from approximately 4 to 5 years before the year 2000 to about 2 years or less at present in the lower Tana River basin. Similarly, the study revealed a general rainfall decrease in the recent years indicating that the region is becoming drier leadingto frequency of droughts in recent years increasing to about 1 to 2 years (Ngaina, et al., 2014) .

Climate variability is also noticeable in West Pokot County with increase in the frequency of prolonged droughts, increase in cases of landslides during flood events, changes in river regimes including river courses, e.g. River Suam in Kongelai and Kacheliba had changed its course, temperature, e.g. Lelan's average temperatures have increased (GOK, 2012). The action plan report also noted reduction of water levels in rivers, e.g. River Weiwei, pasture reduction, floods and siltation of rivers, e.g., River Sigor and R. Sebit, loss of soil to gully and wind erosion and increase in forest fires. Fig. 3.5 shows various mitigation measures against drought impacts in West Pokot County by the community. It is apparent more female respondents tended to recall years of severe drought than male respondents. This could possibly be due to the fact that females are more vulnerable to drought and tend to keep such events in memory much longer than men 


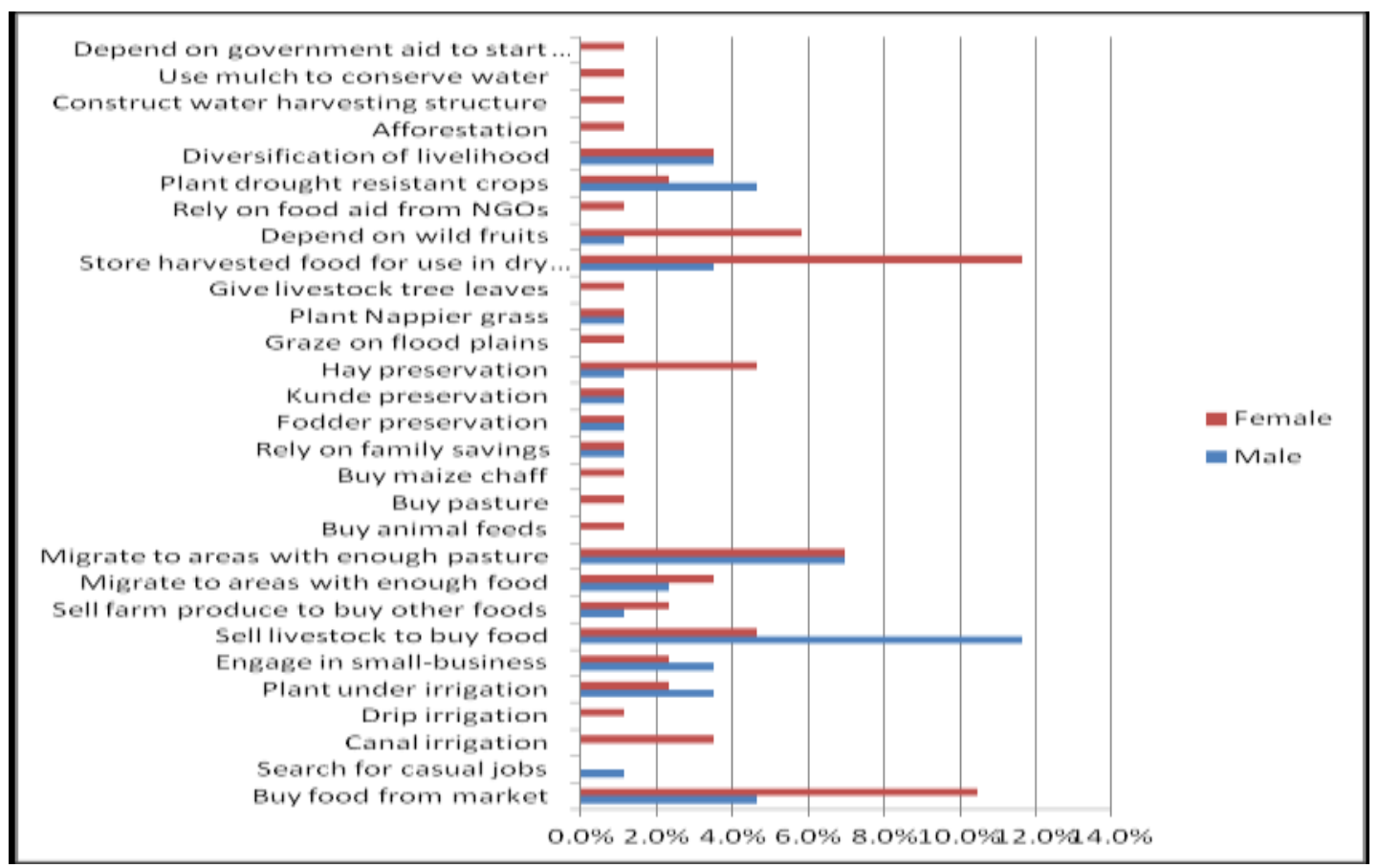

Figure 3.5: Mitigating Drought Impacts by gender for West Pokot County

\subsubsection{Lightning, landslides and Gusty winds}

The study found out that lightning was common in West Pokot County. In 2012 at Chesegon market in West Pokot County lightning struck two students dead and left several injured. Similarly, two other children were struck dead and 11 injured by lightning in July 2016 after a heavy down pour. Livestock was also killed and others injured in Kapkanyuk village in Lelan ward in West Pokot (Global Warming Foundation, 2012). Lightning hazards are frequent in the county. Landslides in Batei ward in West Pokot County were reported in 2012 leading to loss of property. The adaptation technical report 9 of 2012 by the National Climate Change Action Plan also identified strong winds as one of the major hazards in Garissa (National Climate Change Action Plan 2012). In April 2016 a storm unleashed gusty winds and rain in Garissa(Building Resilience and Adaption to Climate Disasters, BRACED 2016). The main causes are from thousands of animals as they make their way to water points and in search of pasture.

\subsection{Current Climatic hazards, impacts and adaptation measures in four Counties}

The study established diversified climate change impacts on human, livestock and crops. Current adaptation and coping measures were identified and documented as detailed in this section. Figure 3.5 shows a general overview of drought impacts on key resources in the four ASAL Counties in order of severity.

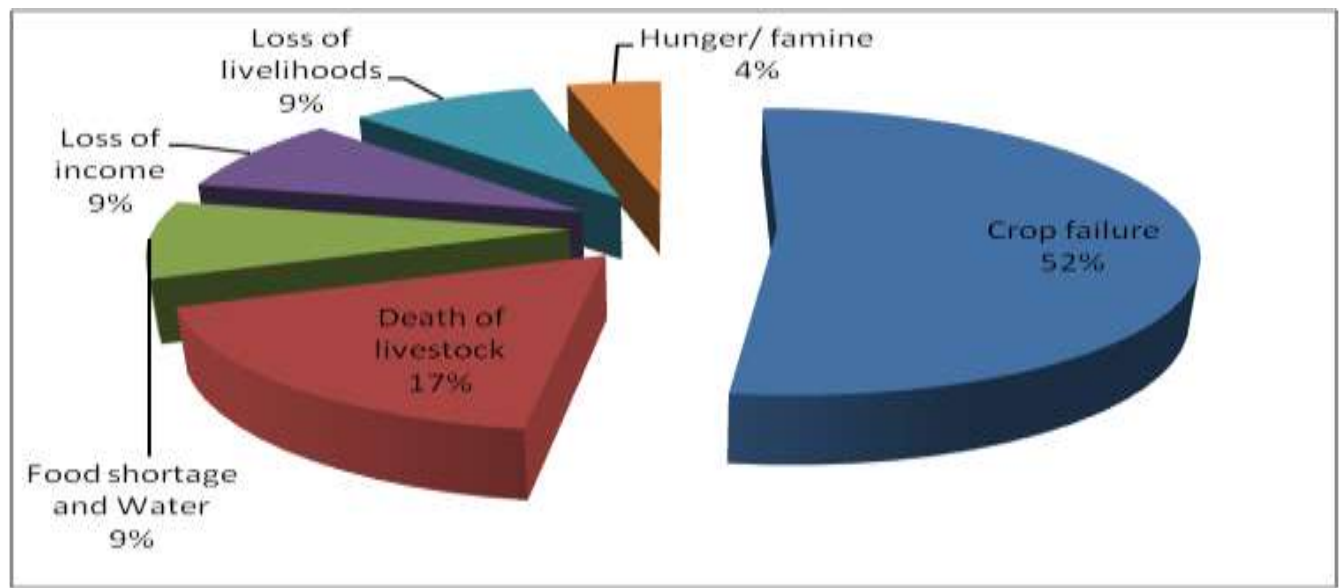

Figure 3.5: Impacts of Drought in Garissa, Tana-River, Kilifi \& West Pokot Counties Source: (field data, 2016) 
In response to climate change in the ASALs, the target communities have adapted to various impacts differently as demonstrated by Figure 3.6

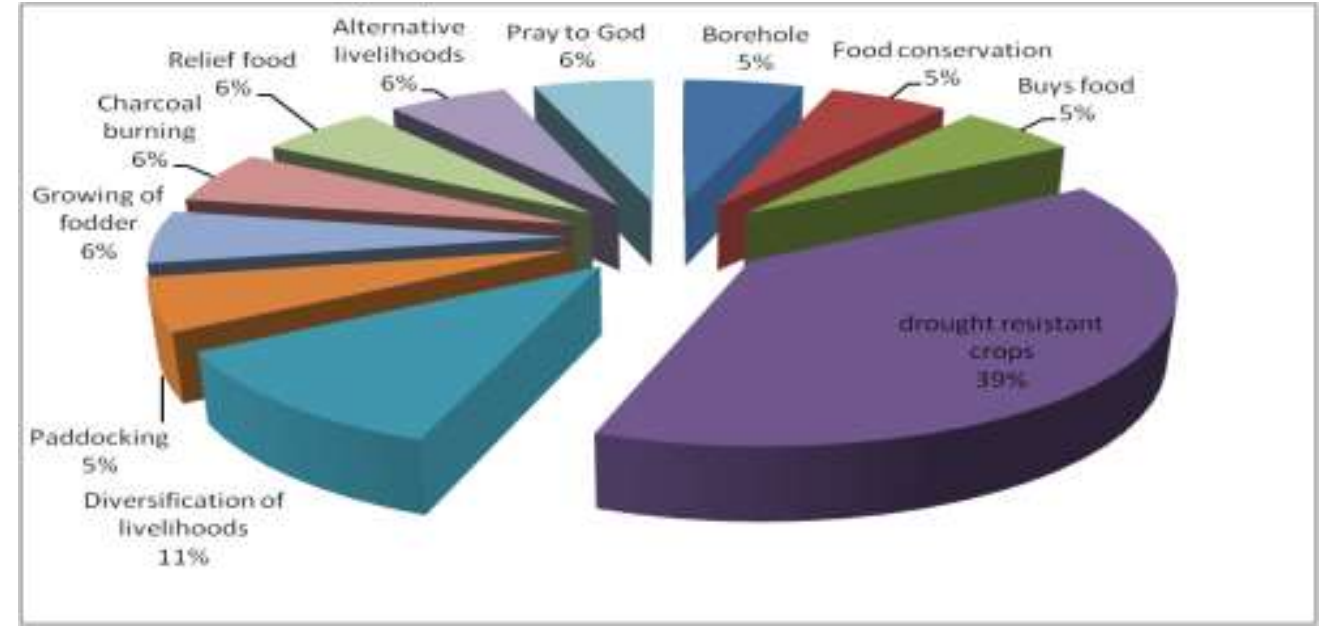

Figure 3.6: Adaptation strategies to Drought in Garissa, Tana-River, Kilifi \& West Pokot Counties Source: (field, 2016)

\subsubsection{Impacts of Drought on Human and Adaptation Strategies (a) Water shortages and pollution}

Drought has resulted to water shortages and pollution, drying of water sources and conflicts in the study areas of Garissa, Tana-River, West-Pokot and Kilifi Counties as indicated in figures $3.7 \&$ 3.8. Water pollution has led to human disease outbreaks rendering the community more vulnerable to climate change. Human diseases associated with water shortage and contamination includes; Amoeba, Brucella, Diarrhea, Typhoid and Cholera. Diseases associated with dry weather conditions include Tuberculosis, colds, flu and malaria.

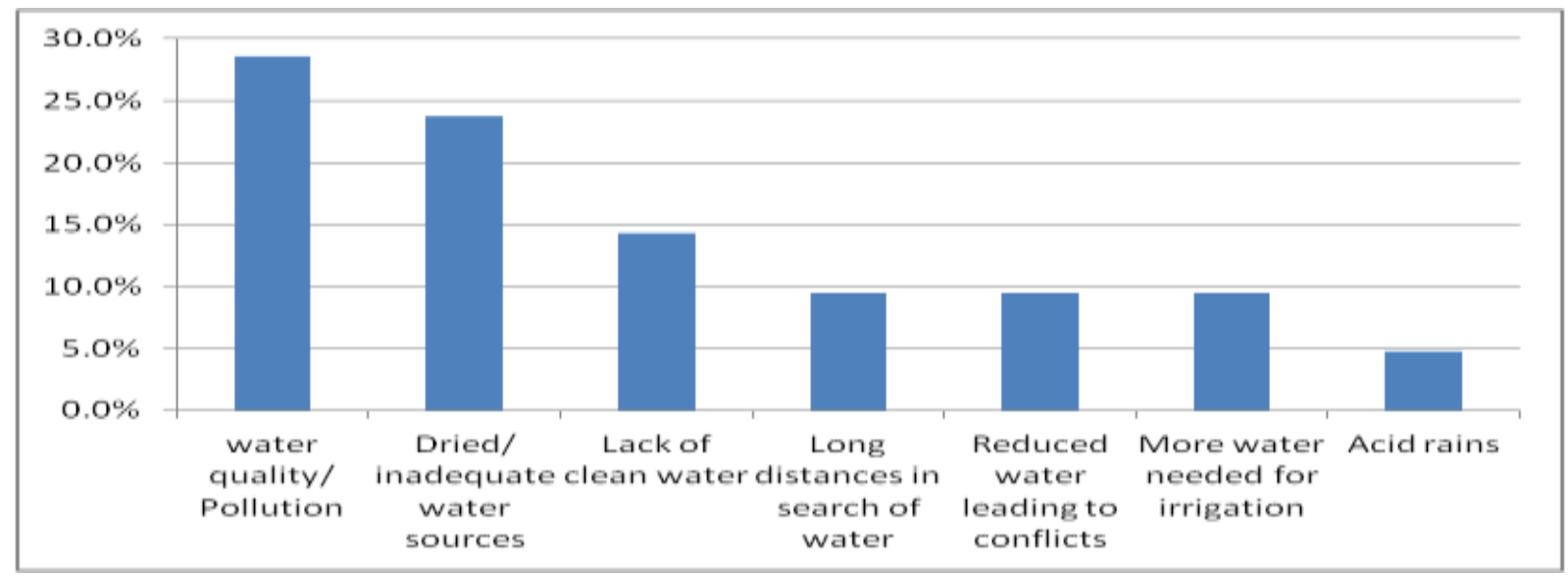

Figure. 3.7: Impacts of Climate Change on water and water use in the Kenyan ASAL

Source: (field data, 2016)

The study revealed various interventions through KACCAL in empowering the community such as through sensitization to construct water pans and adoption of other methods of water harvesting and conservation techniques such as Zai pits, V pits and roof catchment to harvest rain water. Construction of bore holes such as in Ngamano area in Tana River County, construction of tanks and supply of clean water by NGOs such as USAID and German Agro Action (GAA) was clearly evident as an effective adaptation measure. Institutions such as schools with iron roofs have embraced roof water harvesting techniques which was found beneficial to the community. 


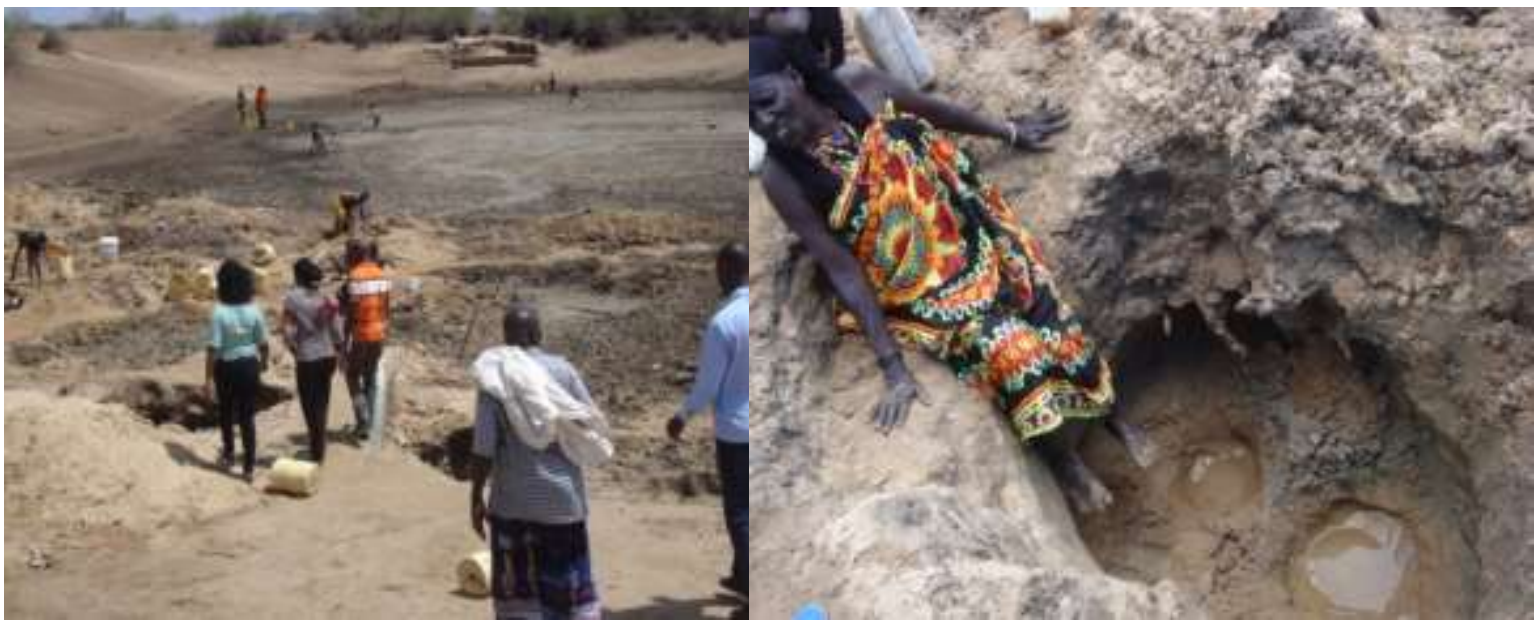

Figure 3.8: Severe water shortages in Gururi in Tana-River County-Digging of Shallow wells for domestic water.

Source: (field data, 2016)

\section{(b) Food shortage and loss of livelihoods}

Prolonged and recurrent droughts as a result of unreliable and inadequate rainfall in the study area have resulted to loss of livelihoods and food shortages (Ref. Figure.3.9).For those who live along water sources such as the river Tana and lagas, it was evident that some farmers have shifted to early maturing crops like green grams and tomatoes sometimes under irrigation. To mitigate drought stress and shocks some farmers and pastoralists destock and sell livestock and farm products like honey, mango and camel milk to generate income to meet other domestic needs. Farmers have adopted both traditional and modern food storage techniques during bumper harvest to sustain them through drought periods. Subsequent crop failure and loss of livestock has edged the local communities to seek alternative livelihoods such as charcoal burning, bee keeping and local poultry.

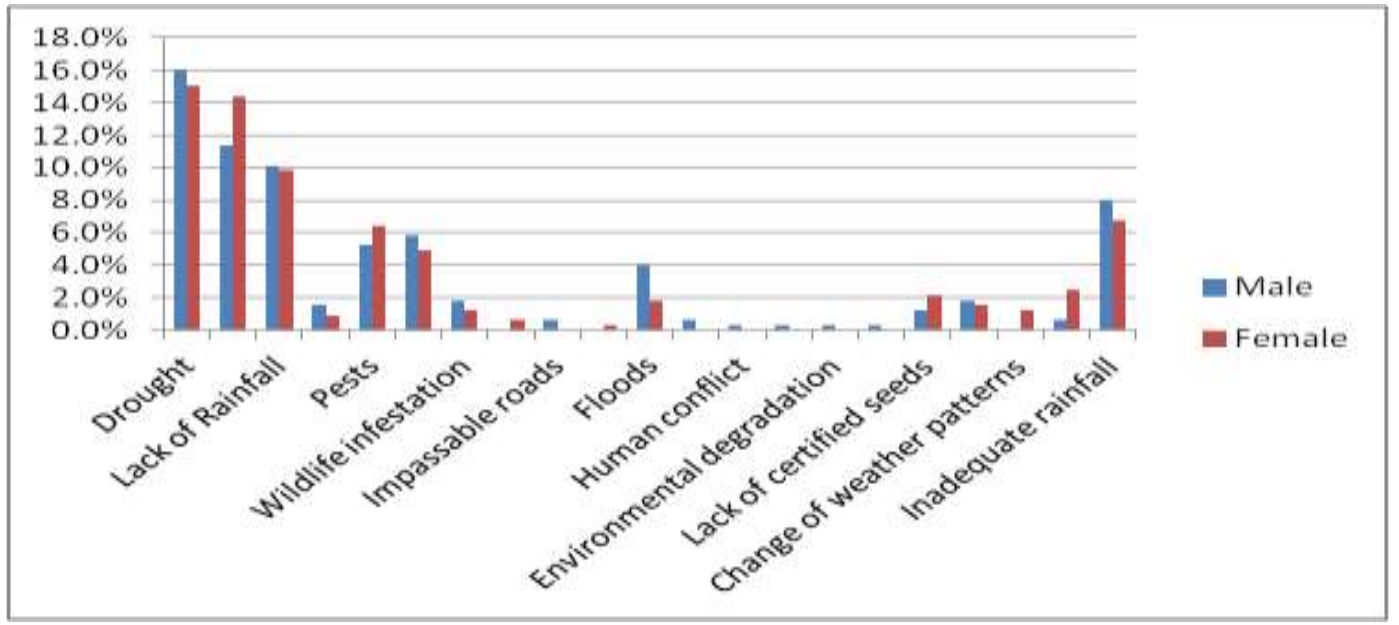

Figure 3.9: Causes of food shortage in Tana-River County

Source: (field data, 2016)

\section{(c) High illiteracy levels}

The study established that drought impacted negatively on the community as many cases of school drop outs and early marriages were reported. Children and youth were reported to drop out of school to assist in searching for food and water. The nomadic culture of the community was also found to interrupt learning hence low literacy levels that were found a hindrance to the adaptation process to climate change impacts. Garissa County reported highest score on illiteracy levels in the study area with female most affected 


\subsubsection{Conflicts between pastoralists and farmers}

As the temperature rise due to prolonged droughts, pastoralists are increasingly forced to infiltrate farm lands which act as fall back zones as was the case in Garsen i.e. Ngao and Kaloleni areas degenerating into conflicts between pastoralists and farmers as livestock destroy crops. Besides, as a result of drought the county is marked with influx of animals from rangelands whose forage is depleted hence exerting pressure to the available resources that results into farmer-pastoralists conflicts and in extreme cases it was reported that sometimes there occurs pastoralists-pastoralists conflicts.

\subsubsection{Impacts of drought on Livestock and adaptation strategies}

Drought has impacted negatively on livestock as a result of inadequate and unreliable rainfall and extreme temperature as discussed under the following sub-sections.

\section{(a) Impacts on Feeding}

The study revealed that drought has affected the feeding patterns in livestock resulting to rangeland and land degradation due to unreliable rainfall, overstocking and poor farming practices. Figure 3.10 confirms decline in pasture as an impact of climate change due to reduced and unreliable rainfalls and overstocking. However, the communities have with time adopted some strategies to overcome animal feed shortage and scarcity as discussed in the following sub-sections;

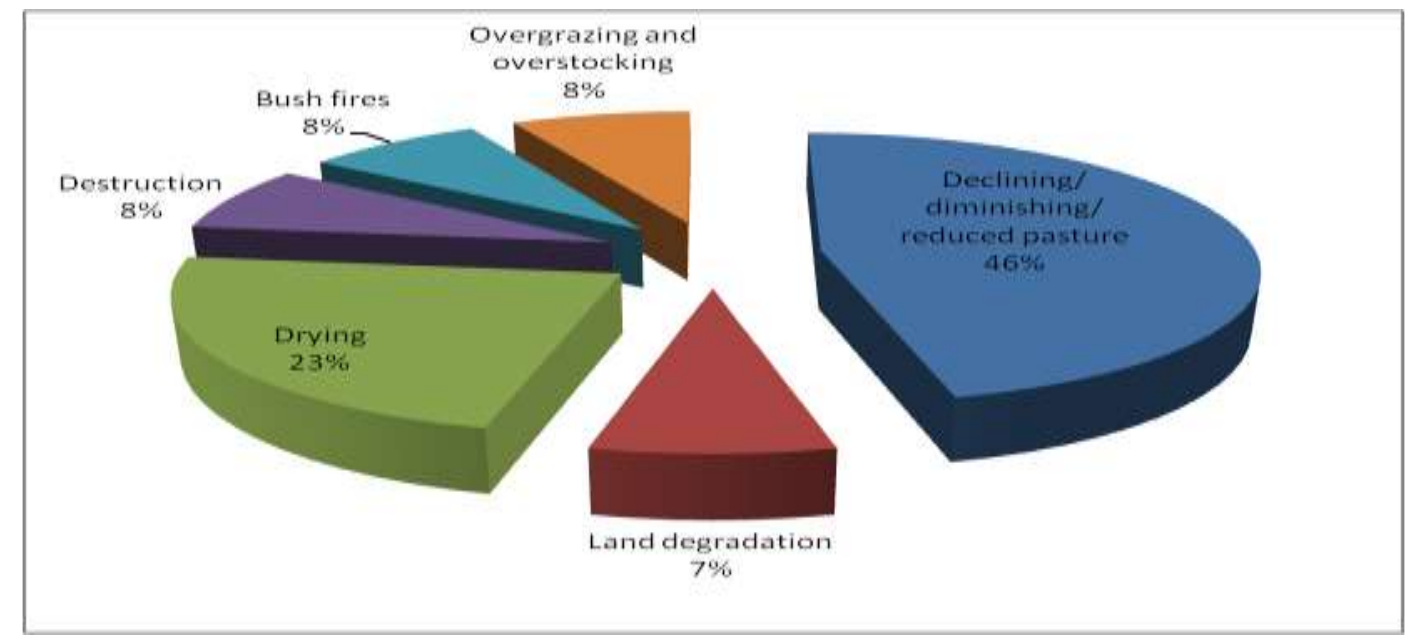

Figure 3.10: Decline in pasture as a result of climate change in the study area.

Source: (field data 2016)

\section{(b) Adaptation/Coping strategies}

\section{(i) De-stocking, sub-division of herds and migration to areas with pastures and water}

Historically pastoralists have adopted animal migration within and outside their areas depending on climatic severity as indicated in the figure 3.11. This movement is usually coined towards accessing water and pastures. The study revealed that most pastoralists mostly sub-divide their herd as they migrate as a survival tactic against pests and diseases and to reduce pressure on available marginal feeds. Figure 3.11 shows an overview of adaptation measures taken by pastoral communities on declining pasture and grass in KACCAL Counties.

In addition the study revealed livestock influx in and out of neighboring counties of Garissa, Kitui, Isiolo, Meru and Kilifi. Livestock markets in Kitui County such as Ukasi, Mutha and Bangali attracted livestock movements. Other points of influence were the livestock markets at Kilifi and Lamu. Movement of animals from Garissa County to Tana-River County was mainly for pasture and water. The Tana-Delta sub-county was found to be a fall back area for livestock feed and water since its always wet and green owing to its proximity to the Indian Ocean. 


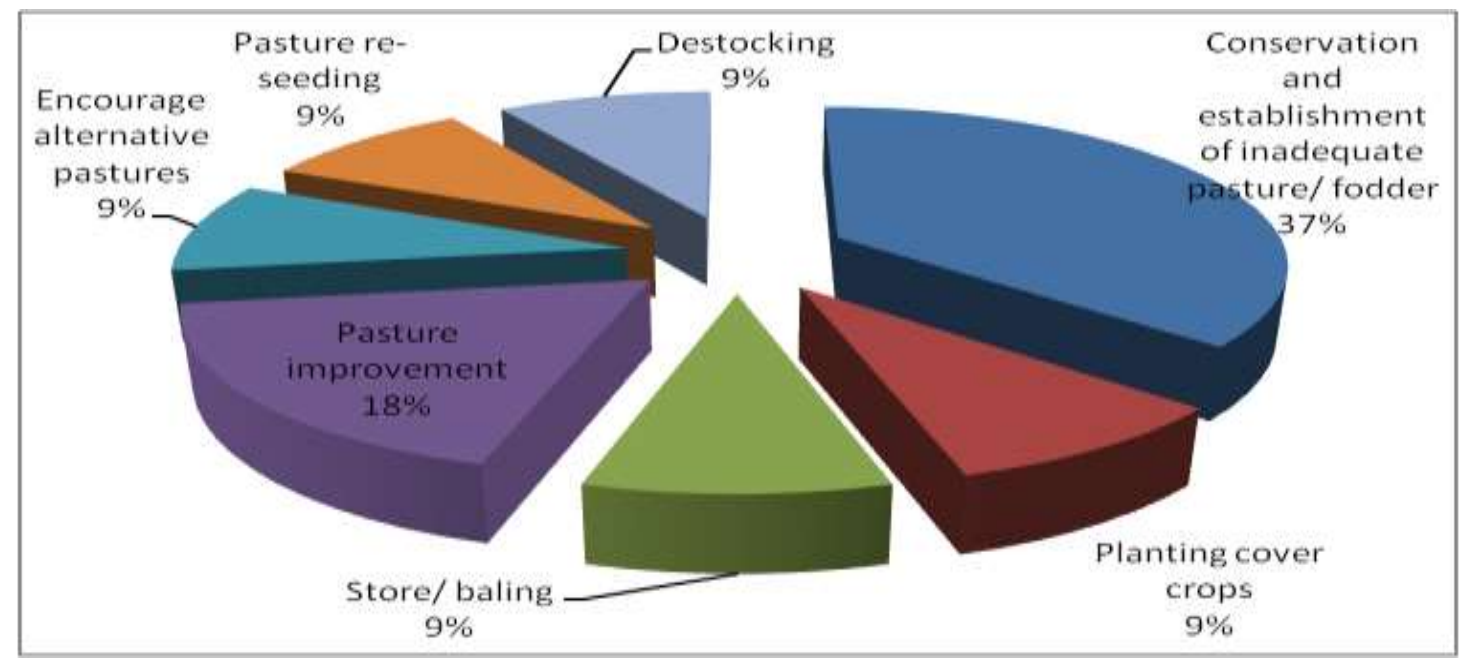

Figure 3.11: Adaptation strategies to declining pasture adopted by KACCAL Project communities Source: (field data, 2016)

\section{(ii) Feed conservation and supplementation techniques}

With the training and empowerment by KACCAL technical staff, pastoralists have espoused forage conservation techniques especially hay bailing and other food supplements such as banana leaves; this is evident especially for goat keeping farmers in Tana North sub-county in Bura-Biskidera catchment who have hay stores, hay bailing pits and boxes. Hay bays are kept in hay stall for feed reservation for use on young, milking herds and the weak during droughts. In Garissa County, farmers are grazing their livestock on pastures obtained from their farms and the animals are fed in enclosures near their farms.

\section{(iii) Establishment of drought resistant fodder crops and pasture}

Besides, some edible trees like acacia, lukena and mathenge have been embraced and are used to feed the young, old and dairy herd. All these tree species are drought resistant thus becoming handy during harsh climate; especially lukena has been planted in farms and homesteads by many farmers in the areas of Bura and Wayu in v-shaped bans which is a commonly adopted technique for water catchment and conservation. The communities along River Tana and along major laggas like Galole have embraced mixed farming to complement their livelihoods and thereafter use the crop remains as fodder for animals e.g. maize cobs and stalks are used as animal feeds and animal wastes used as organic fertilizer in farms.

General adaptation measures to crop failure includes; early planting and harvesting, use of early maturing plants, construction of greenhouses and food conservation during bumper harvests. Livestock adaptation strategies identified by the study includes; de-stocking, fodder conservation, pasture re-seeding and construction of climate smart houses for animals. For apiculture, construction of apiary houses for temperature modification was common, planting of fodder crops and tree planting for flowering.

\subsubsection{Impacts on Livestock Health}

Mortality rates in livestock across the four counties were noted as a key challenge to the pastoralist communities. This is caused by lack of pasture, water, disease infection and infestation by pests. The study revealed that livestock influx during drought and migration season leads to disease outbreaks menace such as foot and mouth, CBPP - (contagious bovine pleural pneumonia), CCPP - (contagious caprine pleural pneumonia), East coast fever, rinder pest, rift valley fever among other resulting to immense losses to pastoralists.

To address this impact, vaccination against diseases was found as the most adopted strategies recording the highest score of 53\%. Other measures includes; controlled grazing, establishment of pasture, controlled movement of livestock, veterinary extension services to the community and best livestock husbandry practices. Use of protective equipments and proper disposal of waste chemical equipment's for their safety and health, keeping of drought and diseases tolerant livestock varieties such as the Orma breeds in cattle, Galla goats, Black headed Persian sheep and the Somali camel breed, controlled grazing and establishment of pasture and fodder to reduce livestock movement. 


\subsubsection{Effects of Drought on Apiculture}

The study revealed extensive impacts by drought on apiculture value chain. This is characterized by high emigration of bees, low bee occupation, reduced bee forage, reduced volumes of honey, long harvesting intervals and a decline in quality of honey. The study eludes these impacts to continued decline in vegetation cover and shrinking diversity especially flowering plants which are the main source of pollen grains and nectar for honey making, being evident. Reduction in natural forest cover and poor farming methods such as use of chemicals and fertilizers in plant production process also affects the quality of honey as well as foraging bees. Modern bee hives were found to be a solution to increased deforestation Most apiculture farms had alternative sources of forage achieved through mixed farming by individual farmers like sun flower and passion fruits, bananas, mango trees, cotton, Bixa and cashew nut trees to sustain honey making process even during dry spells In West Pokot farmers are planting sweet potatoes near apiary houses to support flower and pollen for bees and in turn act as an alternative feed for the livestock using the leaves and a source of food for their families.

\subsection{7: Impacts of Drought on Crops, Fruits and Vegetables (Mango, Bulbs and Onions)}

Crop failure and reduced yields was evident in the study area due to unreliable and inadequate rainfalls and extreme high temperatures. Other challenges includes expensive farm inputs i.e. (fertilizers quality seeds) .Mango production in West Pokot (Sigor) and Tana-river (Ngao) counties was found to be highly affected by inadequate rains. Rainfall failure coupled with shrinking water resources has led to drying of mango trees in areas of Tana-River counties in Ngao-Garsen SubCounty. Harsh climatic conditions in the study area worsening thus encroaching on areas that were used for production of crops such as along the River Tana and dry river valleys/ laggas like lagga Galole. Subsequently, there is increased crop failure even as previously observed productive patches of the county like dried shakababu oxbow lake which was rich in production of rice and fish after floods receded have been wasted and rendered unproductive due to prolonged droughts.

However, some communities have adopted effective strategies to deal with unreliable rainfalls such as through irrigation (drip and farrow) and construction and use of water conservation methods such as Zai pits, digging of shallow wells and encroachment to river banks and lagas. In Tana-River County proximity to the river Tana has benefited the farmers as they are able to irrigate their mango trees. In West Pokot, the community has adopted growing of mangoes in situ as a strategy to deal with extreme climate changes. Other drought resistant crops grown in the county are millet, sorghum and green grams. Adoption of best farming practices such as top working and grafting in mangoes was also evident as a way of improving crop productivity. Also due to increased incidences of crop failure farmers were found to have embraced diversification methods through mixed farming. Farmers have also adopted planting of drought tolerant crops such as green grams and millet.

The study also established post-harvest challenges on crops such as mango, irish potatoes and onions due to high temperatures that lead to a short shelf life and great losses. As a result, farmers have adopted value addition to prolong the shelf life and for conservation during bumper seasons through the use of mango driers to make mango flakes were a new and a fast growing strategy in mango growing areas. Proper drying of Onions was found to prolong the shelf life of onion bulbs and to reduce on most diseases during storage.

Outbreaks of crop diseases were also reported as a result of climate change in the study area such as Maize lethal necrosis, Maize streak virus, Early and late blight in irish potatoes, Powdery mildew, Anthracnose in mangoes, Aphids, Tomato leaf miner and Black antraluose.

\subsection{Impacts of Floods}

Causes of floods in the study area are in a three- fold phase, firstly and fundamentally it's due to river overflow during upstream wet seasons. Secondly, though marginally floods in the county also are said to occur due to erratic rains yielding flash floods. Flood as a climatic hazard in the county stands out because of its consequences to the local livelihoods. The study dissected flood's impacts into both positive and negative. The positive impacts of floods include; floods are the primary natural interjectory which recharges the county's water access points such as water pans, dams, seasonal rivers, the ox-bow lakes of Ngao in Garsenas well as recharge of the underground water stocks which resuscitates pasture growth after long drought spells and on which the little yet life supporting rain fed agriculture depends upon as is the case along laggas and the river Tana..

The formerly rich floodplains in nutrients and moisture for agricultural prudence now are increasingly being encroached by arid like conditions denying the county its fall back patches during the drought for livestock pasture as well as crop production. The broken perennial flooding chain has with equal magnitude also disrupted the fishing sector as it was used also used as ecological trigger for both the spawning and migrating fish species. Whereas some species spawn on the flood plain itself, others migrate upstream to spawn in the river channels, providing an abundant supply of fish and alternative income sources at the household and community levels. The raging flood which often finds the land bare and vulnerably erodible culminates into massive erosion rendering greater parts of the county an unproductive wasteland. Subsequently, 
the study area is characterized by increasing crop failure which is synonymous to food insecurity as majority of the people have to depend on external food sources.

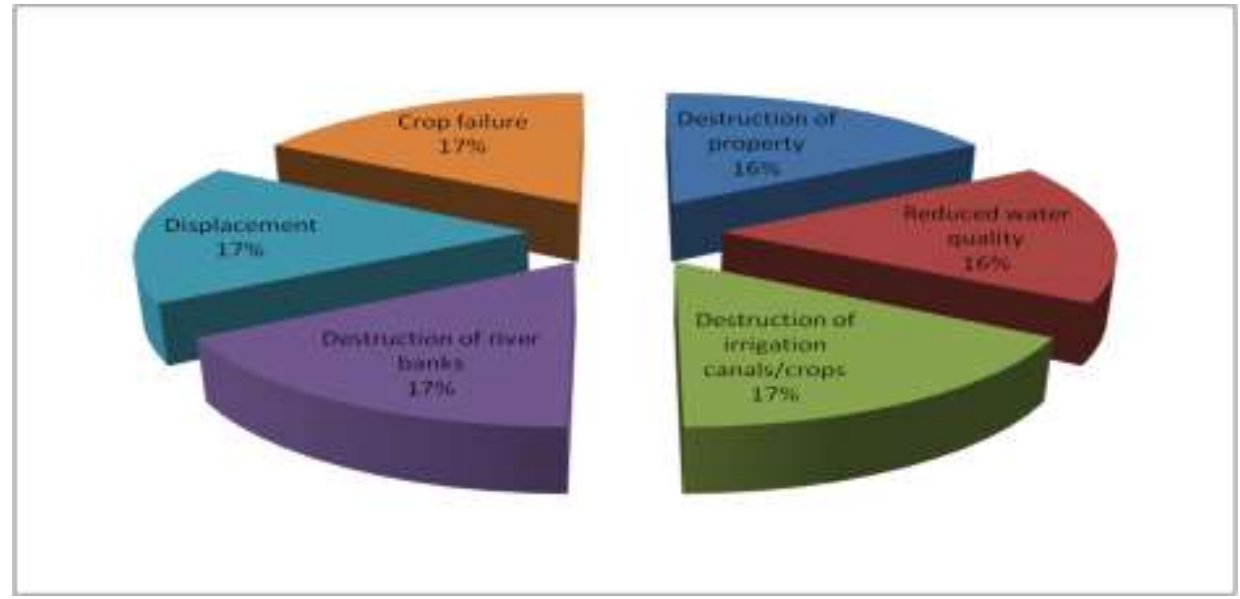

Figure 3.12: Impacts of River Tana Floods in Garissa and Tana-River Counties Source: (field data, 2016)

As figure 3.12 indicates, floods results in loss of property and they cause considerable damage to infrastructure like roads, schools and bridges thus impairing communication as communication lines are grounded for instance electric lines. Floods were found to accumulate waste on land, in homesteads as well as flash excess farm inputs on crop lands; the contaminated flood waters are marked with outbreak of diseases like cholera \& typhoid in human beings and foot and mouth in livestock. Massive losses associated with floods yields stress and shocks resulting into psychological disorder affecting the fragile socio-economic County profile. While in Tana-River County floods area a blessings, the opposite is true for Garissa County where farmers blame their crop failure and their farm undulations to the flood waters from River Tana.

In Kilifi County, rises in sea levels was associated with crop failure, loss of property and income, death and reduced yields. Table 3.1 gives an overview of impacts of floods in percentage form per county ranging from loss of lives, destruction and loss of property, infrastructure, loss of crops and livestock and disease outbreaks both human and livestock.

Table 3.1: A Summary of Impacts of Floods per County in Percentage form

\begin{tabular}{|c|c|c|c|c|c|}
\hline \multicolumn{2}{|r|}{ Counties } & Garissa & Kilifi & Tana River & West Pokot \\
\hline \multirow{5}{*}{ 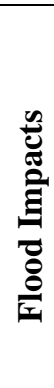 } & Loss of lives/death & $14.1 \%$ & $20.9 \%$ & $16.0 \%$ & $20.5 \%$ \\
\hline & Loss of property & $17.6 \%$ & $17.8 \%$ & $21.4 \%$ & $17.9 \%$ \\
\hline & $\begin{array}{l}\text { Destruction of } \\
\text { infrastructure }\end{array}$ & $22.9 \%$ & $19.6 \%$ & $19.4 \%$ & $26.3 \%$ \\
\hline & Loss of crops/livestock & $31.8 \%$ & $20.7 \%$ & $22.5 \%$ & $26.3 \%$ \\
\hline & Disease outbreaks & $13.5 \%$ & $20.9 \%$ & $20.8 \%$ & $9.0 \%$ \\
\hline
\end{tabular}

Source: (field data, 2016)

\subsubsection{Coping strategies/ mitigations/ interventions}

Garissa and Tana River County's topography reveals an extensive plain, plateau like fields which presents immense challenge in managing flood waters. Nevertheless, the locals have identified some areas that are raised and safer against the floods for habitation. The study also revealed diversified interventions by the stakeholders involved such as food relief, shelter, medication, provision of tents and other basics, moved to higher grounds, building dams among others. To inform evacuation plans and future developments, there is need to create awareness on effects of floods to the community. Besides production and institutionalizing of flood risk maps which help the vast pastoral communities to plan for location of their villages and essential life supporting structures like earth pans and boreholes supply of relief food by Government was 
found to be one of the major interventions in the county. In summary, respondents indicated awareness and knowledge on climate change linking their awareness on features such as continual changes in weather and climatic conditions and environmental degradation.

\section{CONCLUSION}

This study has identified several climate change hazards that affect the livelihoods and survival of farmers and pastoralists inhabiting the four ASAL counties of Garissa, Kilifi, Tana River and West Pokot. Some of these hazards include drought, floods and new human and livestock diseases. According to the study findings, some of the hazards were said to be positive such as flooding although largely destructive. However, it was unanimous in all the four counties that most hazards destroyed crops, led to crop failure or cost communities life and loss of property

it is concluded that the current and potential future climatic hazards in the four semiarid counties under this study are drought and floods followed by landslides .the majors impacts of these climatic hazards to livelihoods were loss of livestock due to lack of pasture and water; loss of crops leading to food insecurity; Reduced sources of income for the community and change of river course during drought hence farmers cannot irrigate during dry spells. Floods have contributed to loss of lives, triggered landslides hampering access to affected areas and displacing entire communities, Water pollution has led to human disease outbreaks rendering the community more vulnerable to climate change. The alternating cycles of droughts and floods do not only destroy the livelihood sources but also severely undermine the resilience of the people living in the affected areas

Positive adaptations established includes significant promotion of smart climate agricultural practices such as; early and timely planting, organic farming and reduced use of fertilizers and chemicals, use of drought and disease tolerant crop varieties, drought and diseases tolerant animal breeds, early maturing varieties, conservation of food stuffs, promotion of improved soil conservation measures, water harvesting and conservation techniques, conservation of available community resources such as forests, rivers and infrastructure. The above have resulted to a more resilient community

some adaptation strategies were found to have negative and detrimental effects to the community resources such as; movement of livestock during droughts results to livestock influx and outbreak of livestock diseases, encroachment to water sources resulted to water abstraction, water pollution and siltation of rivers, cultivation on steep slopes, overstocking and clearing vegetation for charcoal burning led to soil erosion. Continued use of fertilizers may lead to acidic and poor soils hence poor yields

From the study findings, it was apparent that efforts are being made at all levels- that is community, county and national government to address climate change hazards identified in the study. Sustainable adaptation strategies are being adopted to mitigate the negative impacts of climate change identified in the study counties.

\section{STUDY RECOMMENDATIONS}

More awareness should be created among local communities so that they diversify their livelihoods to cope with changing climate. The County and Central governments should redouble their efforts in this direction.

Various stakeholders should be trained on how to use tools and methodologies developed in order to monitor impacts of climate change in their respective counties. In other words, capacity building at community, county and national government should be a top priority.

\section{REFERENCES}

- $\quad$ AEA Group.( 2008). Final Report: Kenya: Climate Screening and Information Exchange. Report to Department for International Development, Issue Number 2, September 2008.

- Agnew, M. \& Goodess, C. (2015). Developing a Conceptual Framework $\left\{2^{\text {nd }}\right.$ DRAFT $\}$, Climatic Research Unit, University of East Anglia, UK retrieved 11 $1^{\text {th }}$ November 2015.

- Bimal Raj Regmi et al (2010) Participatory Tools and Techniques for Assessing

- Climate Change Impacts and Exploring Adaptation Options A Community Based Tool Kit for Practitioners.UKaid

- David Kahan (2008) Farm management extension guide, managing risk in farming Food and Agriculture Organization of the United Nations, Rome 2008.

- Fraser, E. D. G., A. J. Dougill, K. Hubacek, C. H. Quinn, J. Sendzimir, and M. Termansen. (2011).Assessing Vulnerability to Climate Change In dry Land Livelihood Systems: Conceptual Challenges and Interdisciplinary Solutions, Ecology and Society 16(3): 3.

- GoK (2010). National Climate Change Response Strategy (NCCRS), Nairobi.

- GOK. 2012. National Climate Change Action Plan 2013 -2017, Nairobi.

- Hinkel, J. 2011. Indicators of vulnerability and adaptive capacity: Towards a clarification of the science-policy interface. Global Environmental Change, 21: 191-208. 
- IPCC. (2007). Climate Change 2007: Impacts, Adaptation and Vulnerability, Contribution of Working Group II to the Fourth Assessment Report of the Intergovernmental Panel on Climate Change M.L. Parry, O.F. Canziani, J.P. Palutik of, P.J. van der Linden and C.E. Hanson, Eds. Cambridge University Press, Cambridge, UK, pp 976.ISO31000:2009. 2009. Risk Management: Principles and Guidelines

- IDB (2014) Climate Change Data and Risk Assessment Methodologies for the Caribbean, Environmental Safeguards Unit TECHNICAL NOTE No. IDB-TN-633

- $\quad$ Singleton, R.A. Jr., and B.C. Strants. (2005). Approaches to Social Research, 4th ed., Oxford, Oxford University Press

- UNFCCC Secretariat (2004) Compendium on methods and tools to evaluate impacts of, vulnerability and adaptation to climate change. Stratus Consulting Inc. 
ppendix: A Summary of Evidence of Climate Change in the Four KACCAL Pilot Counties

\begin{tabular}{|c|c|}
\hline Evidences of Climate Change & Impacts \\
\hline $\begin{array}{l}\text { - } \text { Changes in rainfall patterns, amount and distribution; recurrent and } \\
\text { prolonged droughts } \\
\text { - } \quad \text { Strong winds } \\
\text { - } \quad \text { Extreme temperatures (high and low) } \\
\text { - } \text { Diminishing surface and ground water levels; e.g RiverBenane and } \\
\text { - } \quad \text { Disappearance/loss of biodiversity } \\
\text { - } \quad \text { Shift from pure pastoralism to agro-pastoralist } \\
\text { - } \quad \text { Emergence and re-emergence of some pests and diseases, e.g., tsetse } \\
\text { flies and trypanosomiasis common in Tana-River county }\end{array}$ & $\begin{array}{l}\text { - Migration of people and livestock in search of water and pasture } \\
\text { - Increase in cost of living/food prices e.g. milk and meat } \\
\text { - } \quad \text { Increased mortality of livestock and wildlife } \\
\text { - Resource based conflicts, e.g. over water and pasture like in Garsen in Tana } \\
\text { - Low productivity of livestock and wildlife } \\
\text { - Loss of livestock leading to loss of livelihoods and increased poverty levels }\end{array}$ \\
\hline Current Actions & Recommended Actions \\
\hline $\begin{array}{l}\text { - } \text { Forest conservation and afforestation and agroforestry } \\
\text { - } \quad \text { Climate change community awareness programmes } \\
\text { - } \text { Protection of water sources and provision/supply of water during } \\
\text { - } \quad \text { Formation of community forest associations (CFAs) alongside charcoal } \\
\text { producers associations (CPAs) to foster sustainable charcoal production } \\
\text { e.g. in Arabuko Sokoke Forest in Kilifi County } \\
\text { - Mainstreaming of climate information into planning processes, e.g. in } \\
\text { - } \text { advocating for alternative livelihoods } \\
\text { - } \text { increasing resource based conflicts e.g. in Garsen - Tana River county } \\
\text { Fodder production, e.g.Rabaikilifi, and Balich, Kone, and Saga in West } \\
\text { - } \text { Pokot } \\
\text { - } \text { sternative energy sources and energy efficiency, e.g. improved } \\
\text { Early warning systems in dealing with particular drought related } \\
\text { disasters } \\
\text { - } \text { Festocking and restocking as measures to deal with droughts } \\
\text { - Sustainable water and land management to build resilience against } \\
\text { droughts }\end{array}$ & $\begin{array}{l}\text { - Strengthening of early warning systems } \\
\text { - Formation of climate change concern committees to spearhead climate change } \\
\text { - } \text { - Strengthening existing environmental management structures } \\
\text { - Mainstreaming of climate change into education and development } \\
\text { - } \text { - Strens/projects } \\
\text { - Increasing access to climate information } \\
\text { - Greater involvement of the media in environmental and climate change } \\
\text { - } \text { Propareness } \\
\text { - Strengthening advocacy/awareness programmes } \\
\text { - Improving governance in NRM } \\
\text { - Implementation existing policies, e.g. policies on farming in riparian zones } \\
\text { - Review of existing policies that conflict with sustainability } \\
\text { - Proper range management including alternative grazing systems } \\
\text { - Implementation of the policy on } 10 \% \text { of individual land for afforestation }\end{array}$ \\
\hline
\end{tabular}

